\title{
ASPECTOS DEL COMERCIO EXTERIOR VALENCIANO EN EL SIGLO XIV (1351-1378)
}

\author{
José HINOJOSA MONTALVO \\ Universidad de Alicante
}

Posiblemente uno de los campos en los que más se ha avanzado en los últimos años y que más bibliografía ha generado en la historia medieval valenciana es el referido al comercio'. Buena parte de los esfuerzos iniciales se centraron en el siglo XV, centuria para la cual la documentación es más abundante y contínua - fondos de Bailía, Maestre Racional o Generalidad en el Archivo del Reino de Valencia-, a la vez que coincide con uno de los momentos más vigorosos de la trayectória histórica de la capital del reino? ${ }^{2}$.

1 La bibliografía es muy extensa. Aquí sólo recojo algunos de los títulos publicados. R. FERRER NAVARRO, La exportación valenciana en el siglo XIV, Zaragoza, 1977; A. FURIO, Editor, València, un mercat medieval, Valencia, 1985; J. HINOJOSA MONTALVO, "De Valencia a Portugal y Flandes", Anales de la Universidad de Alicante. Historia Medieval, 1, 1982, pp. 141-168; «Sobre mercaderes extrapeninsulares en la Valencia del siglo XV", Saitabi, XXVI, 1976; "Las relaciones comerciales entre Valencia e Italia durante el reinado de Alfonso el Magnánimo (coses vedades)", Estudios de Edad Media de la Corona de Aragón, X, 1975, pp. 439-510; "El puerto de Alicante durante la Baja Edad Media», Anales de la Universidad de Alicante. Historia Medieval, 4-5, 1986, pp. 151-166; P. IRADIEL, «Valencia y la expansión mediterránea de la Corona de Aragón», en Catàleg de l'exposició "La Corona d'Aragó. El regne de València en l'expansió mediterrània (1238-1492)", Valencia, 1991, pp. 81-88; o las tesis doctorales inéditas de L. DAVID IGUAL, Valencia e ltalia en el siglo XV. Rutas, mercados y hombres de negocios en el epsacio económico del Mediterráneo occidental, Valencia, Facultat de Geografía e Història, 1995).

2 E. BELENGUER CEBRIA, València en la crisi del segle XV, Barcelona, 1976. 
Menos estudiado ha sido el siglo $\mathrm{XIV}^{3}$, siendo precisamente los años 1351-1378, los que consideramos objeto de análisis, los menos conocidos del periodo, por lo que el objetivo aquí propuesto es aportar una serie de datos que ayuden a conocer mejor este periodo de crisis, a pesar de las limitaciones impuestas por la propia documentación, que se centra en les coses vedades, productos cuya extracción de la ciudad y reino de Valencia se gravaba con un impuesto especial: el dret de treta de coses vedades. Se ha dicho que la utilización de esta fuente para el estudio del comercio valenciano puede crear una distorsión de la realidad y ofrecer una imágen incorrecta del mismo, por cuanto se trata de un comercio marginal, que obvia los productos básicos en los intercambios de la época, como eran el arroz, los tejidos, los granos, lanas, cueros, etc. Tal afirmación es válida y deriva de un uso abusivo de la fuente documental, a la que hay que dar su justa valoración, pero que no por ello hay que relegar al olvido, puesto que nos proporciona noticias sobre el comercio exterior, que van desde el tipo de embarcación y sus patrones a los mercaderes a los puntos de destino.

El hallazgo en el Archivo de la Corona de Aragón de algunos de los libros de cuentas del Maestre Racional, en los que se detalla minuciosamente la salida de la ciudad y el puerto de Valencia de estos productos prohibidos desde 1351 a 1383 nos permite ahondar en este tráfico comercial ${ }^{4}$. Con muchas limitaciones, por supuesto, ya que, como hemos dicho se trata de unas exportaciones muy específicas, con lagunas cronológicas de la propia documentación, que ignoramos por qué en ocasiones quedó inconclusa. De ahí que para completar esta visión de nuestro pasado que podría quedar sesgada hemos recurrido también a las fuentes municipales y los protocolos notariales de la época, que mejoran sensiblemente los fríos datos de una fuente fis$\mathrm{cal}^{5}$.

Los años analizados son los de 1351, 1357, 1359, 1360, 1364 y 1378, un largo periodo de tres décadas correspondientes a la segunda fase del reinado de Pedro el

3 R. FERRER, La exportación valenciana del siglo XIV, Zaragoza, 1977; «Los judíos en el comercio valenciano durante el siglo XIV», I Congreso de Historia del País Valenciano, II, 1980, pp. 553566; “Aportación al comercio valenciano en el año 1391". Estudios de Edad Media de la Corona de Aragón, IX, 1973, pp. 161-183; G. ROMESTAN, cLes marchands languedociens dans le Royaume de Valence pendant la première moitié du XIVe siècle», Bulletin philologique et historique, 1969, I, pp. 115-192; "L'activité des muletiers catalans entre Perpignan et Valence dans la premiere moitié du XIVe siècle», Bulletin philologique et historique, Paris, 1969, pp. 779-795; J. HINOJOSA MONTALVO, "Algunos aspectos del comercio valenciano en 1394", Homenaje al Dr. Juan Reglá Campistol, Valencia, 1975, I, pp. 125-137; D. IGUAL y G. NAVARRO, “Las relaciones económicas entre Valencia e Italia en el siglo XIV», Saggi e Rassegne, 20, 1995. En prensa.

4 A.C.A. Maestre Racional, 1703, 1704, 1705, 1706, 1709 y 1714. Quiero dar las gracias a J.R. Magdalena Nom de Deu que me facilitó la noticia de la existencia de la mencionada fuente.

5 La utilización de los protocolos notariales como base de la investigación y su fiabilidad la ha analizado E. CRUSELLES GÓMEZ, «La intensificación de los intercambios bajomedievales y los protocolos notariales valencianos", 1490: En el umbral de la Modernidad. El Mediterráneo europeo y las ciudades en el tránsito de los siglos XV-XVI, Valencia, Generalitat. Consell Valencià de Cultura, 1994, pp. 523-531. 
Ceremonioso y a lo que se considera como la fase más aguda de la depresión trecentisca, cuyo punto álgido se alcanzó con la epidemia de peste negra de 1348, pero que se repitió con periodicidad casi cíclica en años posteriores.

Son años difíciles, en los que se pasa de lo que se ha calificado como «plenitud medieval» de la primera parte del reinado del Ceremonioso a la "crisis general» con que se clausuró el mismo. Durante un cuarto de siglo el reino de Valencia se convirtió en campo de batalla, no sólo de sus propios conflictos internos, sino de las dos grandes potencias peninsulares: Castilla y Aragón. La guerra de la Unión fue la primera señal de alarma. La guerra con Castilla (1356-1365), en la que se disputa por las comarcas alicantinas del sur, incorporadas a la Corona de Aragón a principio de siglo, fue una importante motivación y actuó como piedra de toque para definir la fortaleza y salvaguardar la integridad del reino de Valencia ${ }^{6}$. El conflicto tuvo graves consecuencias para el reino: despoblación de localidades como Alicante, Alpuente o las comarcas segorbinas, destrucción de cosechas, instalaciones agropecuarias, viviendas rurales y urbanas, presión fiscal, endeudamiento municipal, etc. Si a ello añadimos las catástrofes naturales, como epidemias o hambrunas (1374), lluvias (1358) y un largo etcétera, vemos como el panorama se presentaba difícil para el desarrollo de la actividad comercial, sobre todo marítima, dificultada por la guerra, el corso y la piratería de las potencias contendientes, de los genoveses y los musulmanes.

Pero Valencia no se rindió ante las adversidades. No es casualidad que tras la peste de 1348 los jurados de la capital potenciaran la industria textil, favorecida por la llegada de inmigrantes, hasta convertirse en el eje de la actividad manufacturera urbana. En 1356 los mercaderes de Girona afincados en Valencia fundaron la cofradía de Sant Narcis. Se emprendieron diversas obras públicas, como la restauración del Palau Real por Pedro IV, una vez finalizada la guerra, o se inició en 1380 la casa de la Diputació, y desde 1380 los jurados vieron en el desarrollo del comercio el máximo exponente del progreso de la urbe ${ }^{7}$. La historiografía valenciana muestra unanimidad al considerar que el comercio exterior fue el sector de la economía valenciana que más se desarrolló desde el último cuarto del siglo XIV, una vez asentada la paz en el país, permitiendo integrar a Valencia en la «diagonal insular» mediterránea, que llegaba hasta Sicilia. Una agricultura deficitaria en cereales pero rica en productos para la exportación, al igual que los de su industria local, permitieron la expansión valenciana de finales del siglo XIV y XV. Pero en 1351 los valencianos estaban inmersos en un mar de dificultades.

\section{LOS HOMBRES DE NEGOCIOS}

Los datos dispensados por los libros de coses vedades son demasiado parcos para que podamos aproximarnos a la realidad social del mercader, ya que tan sólo se anotaba el nombre de éste y su procedencia, y no todas las veces.

6 J.V. CABEZUELO PLIEGO, La guerra de los dos Pedros en tierras alicantinas, Alicante, 1991.

7 A. RUBIO, «Ideología burguesa i progrés material a la València del Trecents», L'Espill, 9, 1981, pp. 11-38. 
Por tanto, su mundo socio-profesional se nos escapa y sólo podemos atirbar ligeros trazos del mismo, debiendo profundizar en los protocolos notariales para cubrir tales lagunas. No obstante, recordemos que la denominación de «mercader» que acompaña a cuantos participaban en este comercio, no implicaba su dedicación exclusiva al ejercicio de la mercadería, pues, como veremos, hay desde marineros, que aprovechaban sus viajes para hacer algún negocio, a espaderos que iban vendiendo su producción de pueblo en pueblo, como los viejos mercaderes itinerantes. Por tanto, procedencia y profesión, son las únicas variables que ahora podemos analizar.

Respecto al origen, agrupados por países, tenemos:

\begin{tabular}{|c|c|c|}
\hline Reino de Valencia & Baleares & Sin especificar, 66 \\
\hline Valencia, 189 & Mallorca, 128 & \\
\hline Denia, 1 & Ibiza, 11 & Francia \\
\hline San Mateo, 1 & Menorca, 5 & Narbona, 12 \\
\hline Castellón, 1 & TOTAL, 66 & Agde, 4 \\
\hline Peñíscola, 5 & & Montpellier, 3 \\
\hline \multirow[t]{2}{*}{ TOTAL, 206} & & Beziers, 1 \\
\hline & & TOTAL, 20 \\
\hline Cataluña & Castilla & Italia \\
\hline Barcelona, 29 & Cádiz, 1 & Cagliari, 1 \\
\hline Castelló d'Ampuries, 7 & Castilla, 1 & Italiano, 1 \\
\hline Collioure, 26 & Galicia, 1 & TOTAL, 2 \\
\hline Figueres, 1 & Noya, 1 & \\
\hline Girona, 9 & Sevilla, 3 & Portugal \\
\hline Llançà, 1 & Tarifa, 4 & Lisboa, 1 \\
\hline Montcada, 1 & TOTAL, 11 & Portugués, 1 \\
\hline \multicolumn{3}{|l|}{ Palamós, 2} \\
\hline Perpiñán, 10 & Aragón & \\
\hline Serinyà, 1 & Hijar, 1 & \\
\hline \multicolumn{3}{|l|}{ Tarragona, 8} \\
\hline \multicolumn{3}{|l|}{ Tortosa, 2} \\
\hline TOTAL, 105 & & \\
\hline
\end{tabular}

Las cifras son elocuentes y muestra en estos años un claro control de este tráfico marítimo de productos prohibidos por parte de los mercaderes valencianos, que comercian con los diferentes puntos de destino en el área del Mediterráneo occidental e incluso el Atlántico. Recordemos que los de San Mateo y Castellón exportaban sus mercancías por los cargaderos de Peñíscola y Castellón, lo que originaba un choque de competencias con el Maestre Racional de Valencia, como en 1359 en que envió una barca armada a Castellón de la Plana para que trajera a Valencia algunos mercaderes y patrones de embarcaciones que se llevaban productos prohibidos desde aquél puerto con licencia del procurador del conde de Trastámara, a la sazón señor de la villa, lo que era ilegal, puesto que el señor de la villa carecía de autorización para conceder tales licencias ${ }^{8}$.

8 A.C.A. Maestre Racional, 1705, fol. 56 r. 
Le siguen en importancia los mallorquines y catalanes, procedentes de aquellas localidades hacia donde se enviaban este tipo de productos. Son gentes que vienen a Valencia a cargar otros productos y a descargar mercancías de sus país, igual que los del Midí francés, castellanos, etc. y que al regreso junto a los productos mayoritarios que se llevaban, como por ejemplo los paños, embarcan también algunas coses vedades. Su número está en proporción con la importancia de cada destino y su evolución anual es la siguiente:

\begin{tabular}{|lrrrrrrr|}
\hline & 1351 & 1357 & 1359 & 1360 & $\mathbf{1 3 6 4}$ & $\mathbf{1 3 7 8}$ & TOTAL \\
\hline Mallorca & 33 & 15 & 9 & 17 & 12 & 42 & 128 \\
Valencia & 50 & 24 & 11 & 15 & 8 & 81 & 189 \\
Collioure & 4 & 4 & - & 4 & 4 & 10 & 26 \\
Sin especificar & 29 & 20 & 4 & 1 & - & 12 & 66 \\
Barcelona & 5 & 1 & - & 1 & 2 & 20 & 29 \\
Castilla & 1 & - & - & - & - & - & 1 \\
Castelló d'ampuries & 4 & - & - & - & 1 & 2 & 7 \\
Hijar & 1 & - & - & - & - & - & 1 \\
San Mateo & - & - & - & - & 1 & 1 & 2 \\
Ibiza & 3 & - & - & - & - & 6 & 11 \\
Perpiñán & 2 & - & - & - & 1 & 7 & 10 \\
Gerona & 2 & 3 & - & 1 & - & 3 & 9 \\
Castellón & - & - & - & - & - & - & 1 \\
Narbona & 6 & 2 & - & - & - & 4 & 12 \\
Palamós & 1 & 1 & - & - & - & - & 2 \\
Tarragona & 3 & 1 & - & 2 & - & 2 & 8 \\
Agde & 1 & 2 & - & 1 & - & - & 4 \\
Sevilla & 1 & - & - & - & - & 2 & 3 \\
Figueres & - & - & - & 1 & - & - & 1 \\
Menorca & 3 & 1 & - & 1 & - & - & 5 \\
Montpellier & 1 & - & - & 1 & - & 1 & 3 \\
Llançà & - & 1 & - & - & - & - & 1 \\
Serinyà & - & 1 & - & - & - & - & 1 \\
Peñiscola & - & - & - & - & - & - & 2 \\
Tarifa & - & 1 & - & - & - & 3 & 4 \\
Denia & - & - & 1 & - & - & - & 1 \\
Tortosa & - & - & - & - & - & 2 & 2 \\
Caller & - & - & - & - & - & 1 & 1 \\
Perelada & - & - & - & - & - & 2 & 2 \\
Blanes & - & - & - & - & - & 2 & 2 \\
Sant Feliu & - & - & - & - & - & 3 & 3 \\
Beziers & - & - & - & - & - & 1 & 1 \\
Galicia & - & - & - & - & - & 1 & 1 \\
Montcada & - & - & - & - & - & 1 & 1 \\
Noya & - & - & - & - & - & 1 & 1 \\
Portugal & - & - & - & - & - & 1 & 1 \\
Cádiz & - & - & - & - & - & 1 & 1 \\
Italia & - & - & - & - & - & 1 & 1 \\
Lisboa & - & - & - & - & - & 1 & 1 \\
Vilafranca & - & - & - & - & - & 1 & 1 \\
\hline
\end{tabular}


Puede verse que aunque las localidades de origen son cerca de cuarenta, en realidad sólo seis superan la decena de mercaderes: Valencia, Mallorca, Barcelona, Collioure, Ibiza y Narbona, a su vez principales destinatarios del comercio marítimo valenciano de productos vedados. A partir de 1378 las cifras de 1351 se superan ampliamente en la mayoría de los casos, como Barcelona, que de cinco mercaderes en 1351 pasa a veinte en 1378.

El comercio terrestre ofrece el siguiente cuadro en 1378:

\section{VALENCIA, 6}

CASTILLA

Castilla, 13

Chinchilla, 3

Castillo de Garimuñoz, 2

Huete, 2

Cuenca, 2

Requena, 1

Alcaraz, 1

Jumilla, 1

Moya, 1

Sevilla, 1

Uclés, 1

TOTAL, 29
ARAGÓN

Teruel, 3

Albarracín, 2

Linares, 1

Mosqueruela, 1

Mora de Rubielos, 1

Alcalá de la Selva, 1

Sarrión, 1

TOTAL, 10

SIN ESPECIFICAR, 25

\section{CATALUÑA,}

Gerona, 1

Es un comercio controlado por los mercaderes castellanos y valencianos, ya que muchos de los que no especifica su origen eran valencianos. Aquí la correspondencia entre los lugares de origen y los destinos era más frecuente que en el comercio marítimo.

Profesionalmente hay de todo, desde mercaderes a estudiantes o clérigos, si bien la mayoría son mercaderes, aunque a menudo el dato lo omita el escribano.

Mercaderes, 339

Sin especificar, 93

Patrón de barca, 11

Patrón de coca, 6

Marinero, 5

Carpintero, 1

$\begin{array}{ll}\text { Patrón de leño, } 3 & \text { Canónigo, } 1 \\ \text { Presbítero, } 3 & \text { Espadero, } 1 \\ \text { Cambiador, } 1 & \text { Pescador, } 1 \\ \text { Candelero, } 1 & \text { Freire, } 1 \\ \text { Estudiante, } 1 & \text { Patrón de Mujeres, } 7\end{array}$

ànfil, 1

Entre el clero aparece un presbítero, Bernat Alegret, en 1351, que se llevó velas de sebo a Menorca; en 1357 Ramón Solsona, vicario de Santo Tomás de Valencia, que exportó seis maderos a Tarragona; en 1359 Guillem de Guimerà, freire del Hospital, se llevó velas a Tarragona; en 1364 Bernat Carreres, canónigo de Valencia, sacó velas para Mallorca, y en 1378 fue el rector de Moncada el que se llevó velas a Aviñón. Tampoco faltaron las mujeres, que en un total de siete, en 1378 enviaron estopa de cáñamo y velas a Ibiza y a Mallorca. En todos los casos se anotaba el nombre del marido. 
En ocasiones estos mercaderes eran factores de otra persona, por cuya cuenta negociaban, como en 1351 Berenguer Soler, negociador de Bernat Meles, mercader de Valencia.

En el terreno de las minorías confesionales, los únicos que merecen destacarse son los judíos, cuya dedicación a las actividades mercantiles es ya provervial. En el comercio de productos prohibidos por vía marítima su presencia es esporádica, con media docena de individuos comerciando con Mallorca. Son en 1351 Modahay Aarón y Hayo Faquim, mallorquines que se llevaron pez; en 1360 Sabado Ableç, de Denia, y Jahudà Benyahuda, de Mallorca, que sacaron 25 dobleras y alquitrán hacia Mallorca, y en 1364 Adzarra, de Mallorca, y Haim Morcat, de Valencia, que extrajeron velas para alumbrar rumbo a Mallorca.

La reactivación que se produjo en los años setenta se plasmó en una mayor presencia de mercaderes hebreos comerciando con estos productos. Por entonces los judíos valencianos, superadas las dificultades generales de la época, entraron en una etapa de desarrollo y prosperidad, que ya analizamos ${ }^{9}$, visible en las protestas que los procuradores de Valencia expusieron al monarca en las Cortes de 1369-70, quejándose del excesivo crecimiento de la judería de la capital del reino, trayectoria que se quebró definitivamente con los violentos asaltos de 1391.

Pero ello quedaba aún lejos y los judíos tenían en Valencia un excelente mercado para aprovisionarse, al que acuden, junto a los de la propia ciudad, mallorquines, de Tarragona y, sobre todo, castellanos. En total 19 judíos, cifra importante si tenemos en cuenta lo incopleto de la documentación, y su presencia fue en aumento hasta $1391^{10}$.

Los valencianos son: Salamó Sibili, que en dos ocasiones exportó muebles y madera a Tarifa (armarios, arquibanco con media doblera, una cuna, una mesita con doblera); Isach Dolell se llevó a Mallorca cáñamo; y Vidal Paci en dos viajes envió dobleras y velas a Mallorca. De Tarragona procedía Salamó, que extrajo seis arrobas de pez, mientras que Isach Abram y Fayo, ambos de Mallorca, regresaron a su ciudad con velas y dobleras. Por último, Gento de Tarifa volvió a su localidad de origen con una cama. Tengamos presente siempre que estos productos que sacaban eran una parte de las operaciones que realizaban en Valencia, cuyo contenido, por otra parte ignoramos de momento.

Por tierra todos los judíos proceden de Castilla, salvo Mossé, de Teruel, que se llevó 12 puñales; del Castillo de Garimuñoz, en la Mancha conquense, vinieron Jucef y Jacobo, que sacaron cuchillos e hilo de palomar; Abrafim de Jumilla se llevó puñales y cuchillos, mientras que Jafudà de Sevilla extrajo 36 cuchillos; Bono de Uclés otros 6 puñales; Jafudà Caloxar, de Chinchilla, hizo dos viajes a su pueblo con 36 puñaes, mientras que otros hebreos se engloban genéricamente como "de Castilla»: Gento Zagel (4 puñales), Jacobo (4 puñales a Toledo), Bono (5 puñales), Gento (6 puñales).

9 J. HINOJOSA MONTALVO, “La comunidad hebrea en Valencia: del esplendor a la nada (1377. 1391)», Saitabi, XXXI, 1981, pp. 47-72.

10 R. FERRER NAVARRO, Los judíos en el comercio valenciano. En 1381 fueron 44 los mercaderes judíos y en 1387 la cifra fue de 79. p. 560 . 
Así pues, Castilia y Mallorca se configuran como los principales focos de comerciantes judíos, en directa relación con la importancia que las comunidades judías tenían en estos reinos y con las líneas del comercio exterior valenciano. La fama de las armas valencianas hacía de la capital del reino un mercado atractivo para los judíos.

\section{TENDENCIA HACIA LA DIVERSIFICACIÓN DE PRODUCTOS}

Dentro de las peculiaridades de este comercio, la principal de las cuales es la de tener la condición de prohibidos, conviene hacer algunas consideraciones para este periodo. En primer lugar, la documentación hace referencia prácticamente al comercio marítimo, y sólo desde 1378 hay datos para el comercio terrestre, lo que nos da una visión fragmentaria del mismo, algo que hay que tener siempre presente. En algunos casos, al principio, el Maestre Racional anotaba al margen del primer folio una sumaria tabla de los productos que estaban gravados y su carga fiscal ${ }^{11}$.

La cantidad de productos exportados en estos años es muy exigua:

\begin{tabular}{|lccccc|}
\hline 1351 & 1357 & 1359 & 1360 (incompleto) & 1364 (incompleto) & 1378 \\
15 & 16 & 8 & 6 & 5 & 29 (mar) \\
& & & & & 21 (tierra) \\
\hline
\end{tabular}

Teniendo en cuenta que muchos de estos artículos a veces no sin sino variedades de un mismo producto, vemos que la realidad cotidiana se circunscribe a unas cuantas mercancías: pez, sebo, velas, alquitrán, metales, derivados de la madera, etc.

A la cabeza se situaba la pez, con estas cifras:

\begin{tabular}{|lrrrrrc|}
\hline & 1351 & 1357 & 1359 & 1360 & 1364 & 1378 \\
\hline Quintales & 1587 & 565 & 176 & 82 & 216 & 688 \\
Arrobas & 16 & 1 & - & - & - & 16,5 \\
Libras & 31 & - & - & - & - & 74 \\
\hline
\end{tabular}

Para años posteriores R. Ferrer señala que entre 1381 y fines de siglo se exportaron 810 quintales, representando unos porcentajes anuales del 12 al $31 \%$ de las exportaciones marítimas de coses vedades ${ }^{12}$.

La cota más alta se alcanzó en 1351 con 1.587 quintales, de los que 744 (46,8\%) se enviaron a Mallorca, donde la actividad marítima y la construcción naval originaban

11 A.C.A. Maestre Racional, 1705, fol. 15 r. Así, en 1359 leemos: «Appar per comptes passats que per treta de les coses davall scrites se donen les quantitats següents, és a saber: per 1 doblera, 1 sou; per 1 tirant, 3 sous; per 1 carretada, 2 sous; per 1 madero, 8 diners; per 1 quintar de seu o de candeles, 2 sous; per 1 quintar de pega, 2 sous; per 1 quintar d'alquitrà, 1 sou; per 1 quintar de ferre, 1 sou; per 1 quintar d'acer, 2 sous; per 1 quintar de canem, 2 sous; per 1 quintar de canem e de exarcia, 2 sous".

12 R. FERRER NAVARRO, La exportación valenciana, p. 232. 
un alto consumo; 563 quintales a Collioure $(35,4 \%), 150$ a Algeciras $(9,4 \%), 88$ a Tarragona (5.5\%), 33 quintales se destinaron a las propias embarcaciones, y otros 9 a Lisboa.

En 1357 Mallorca con 222 quintales y Collioure con 142 quintales mantuvieron la tónica anterior, si bien esta localidad rosellonesa fue superada por Portugal que importó 161 quintales de pez valenciana, mientras que a Tarragona se fueron $30 \mathrm{Qm}$. Curiosamente en 1359 ninguno de los asientos conservados con destino a Mallorca contiene pez, que es absorbida en su casi totalidad por Collioure: $140 \mathrm{Qm}$, y otros 36 hacia Agde. En 1360, de nuevo Mallorca y Collioure acapararon las exportaciones, pero en 1364 se produjo una importante novedad, al destinarse casi toda la pez a Barcelona $(200 \mathrm{Qm})$, tendencia que continuó en $1378(486 \mathrm{Qm})$, frente a 58 quintales enviados a Mallorca. Otros puertos catalanes que compraban cantidades menores e pez en Valencia eran Rosas, Sant Feliu y Tarragona.

En resumen, a mediados de siglo Mallorca y Collioure son los principales receptores de pez valenciana, con salidas esporádicas hacia el litoral atlántico. A partir de 1378 Barcelona pasó a ser el primer cliente de Valencia, seguida de otros puertos catalanes y Mallorca, en un claro comercio triangular interregional, uno de cuyos vértices es Valencia.

Las velas de sebo valencianas eran también objeto de una intensa exportación, como se ve en el siguiente cuadro:

\begin{tabular}{|lrrrrrr|}
\hline & 1351 & 1357 & 1359 & 1360 & 1364 & 1378 \\
\hline Quintales & 98 & 36 & 10 & 5 & 28 & 106 \\
Arrobas & 77 & 59 & 14 & 11 & 12 & 302 \\
Libras & 121 & 83 & 2 & - & - & 330 \\
\hline
\end{tabular}

La tónica es similar al principio y final del periodo, en torno a los cien quintales anuales. La caida intermedia, además de la falta de datos, quizá se relacione con la guerra de Castilla, igual que sucedió con otros artículos. A partir de 1382 supondrán porcentajes generalmente por encima del $10 \%$ del total de las salidas de los productos prohibidos valencianos.

Extraidas en pequeñas cantidades, Mallorca era el gran centro receptor, casi con carácter de monopolio. A partir de 1378, estabilizada la situación política, los envíos se diversificaron y Collioure recibió también importantes remesas, mientras que pequeñas partidas fueron a parar a los puertos al norte del Ebro, como Barcelona, Rosas, Sant Feliu, Agde, etc.

Otras mercancías exportadas fueron el sebo, el alquitrán, enviado a Rosas, BarceIona, Collioure, Sant Feliu y, sobre todo, a Mallorca.

A esta reducida gama de productos se añade la madera elaborada (hojas de pino, maderos llamados tirantes, vigas, dobleras, etc.) hacia Mallorca y Tarragona, Tarifa; cáñamo, hilo de cáñamo, armas (dardos, lanzas, astas de dardos), acero y algún mueble. 
En 1378, aunque por mar se siguieron exportando los citados productos, la inclusión del comercio terrestre diversificó el panorama de los artículos objeto de demanda: armas (puñales y espadas); metales (hierro, cobre, acero); alimentos (arroz y aceite), productos manufacturados (cuchillos, claderas), muebles, cuyo volumen estudiaremos con detalle en el siguiente apartado. En algún caso los artículos extraidos eran de uso personal, como los dardos que en 1378 se llevaba Martí de Villero y sus compañeros "per defensió de lurs persones»"

\section{LAS RUTAS DEL COMERCIO EXTERIOR}

Entre 1351 y 1364 la documentación conservada sólo contiene referencias a los productos exportados por vía marítima. Es imposible conocer la trayectoria seguida por el comercio terrestre, aunque los años de guerra con Castilla trajeron el cierre de las fronteras y la interrupción de los intercambios mercantiles. Lo que sucedió con Aragón o Cataluña lo ignoramos. En cambio, en 1378 el número de viajes por tierra fue de 73 , frente a 260 por mar, lo que supuso el $28 \%$ del total, cifra provisional por cuanto no sabemos si el volumen quedó concluso y, por tanto, lo que nos ha llegado del comercio terrestre es sólo una parte del total. En cualquier caso, lo destacable es que el tráfico terrestre se ha recuperado tras la paz entre ambas coronas de Castilla y Aragón, y que en 1381 muestra una cierta supremacía numérica sobre el maríti$\mathrm{mo}^{14}$.

NÚMERO DE SALIDAS ANUALES

\begin{tabular}{|lcccccc|}
\hline & 1351 & 1357 & 1359 & 1360 & 1364 & 1378 \\
\hline MAR & 174 & 86 & 25 & 50 & 36 & 260 \\
TIERRA & - & - & - & - & - & 73 \\
\hline
\end{tabular}

\section{a) La vía marítima}

Hasta 1378 no son muchos los puertos a los que Valencia enviaba productos prohibidos, un total de 35, localizados prácticamente todos en las islas Baleares y en el área de Cataluña-Languedoc, con algunas extensiones por el sur hacia los puertos de la Baja Andalucia y Portugal y por el Norte hacia Génova o Aviñón, pero sin apenas relevancia. Todo este tráfico se condensa en el triángulo Valencia-Mallorca-BarcelonaCollioure. De hecho, hasta 1364 la concentración es todavía mayor y sólo Mallorca, Collioure y Tarragona destacan sobre la mediocridad restante. A partir de 1378 se mencionan por vez primera más de una decena de localidades, de las que tan sólo

13 A.C.A. Maestre Racional, 1714, fol. 152 v.

14 R. FERRER NAVARRO, La exportación valenciana. En 1381 el total de exportaciones de coses vedades fue de 1584 asientos, de los que 1102 salieron por tierra. 
destacará Barcelona, situada como segundo puerto importador a continuación de Mallorca. En el siguiente cuadro podemos contemplar dicha evolución:

\begin{tabular}{|c|c|c|c|c|c|c|c|}
\hline & 1351 & 1357 & 1359 & 1360 & 1364 & 1378 & TOTAL \\
\hline AGDE & - & - & 1 & 1 & - & 2 & 4 \\
\hline AIGUES MORTES & 1 & 一 & - & - & - & - & 1 \\
\hline ALGECIRAS & 4 & - & - & 一 & - & - & 4 \\
\hline ARLET & - & - & - & 1 & - & - & 1 \\
\hline AVIGNON & - & - & 一 & - & - & 2 & 2 \\
\hline BARCELONA & - & - & - & 1 & 4 & 30 & 35 \\
\hline BEZIERS & - & - & - & - & - & 1 & 1 \\
\hline BLANES & - & - & - & - & - & 1 & 1 \\
\hline CADAQUES & - & - & - & - & - & 1 & 1 \\
\hline CÁDIZ & - & 1 & - & - & - & - & 1 \\
\hline CAGLIARI & - & - & 一 & - & - & 1 & 1 \\
\hline CASTELLO D'AMPURIES & - & - & - & - & 1 & 2 & 3 \\
\hline COLLIOURE & 40 & 6 & 3 & 6 & 3 & 21 & 79 \\
\hline FIGUERAS & - & - & - & 1 & - & - & 1 \\
\hline GALICIA & 1 & 1 & 1 & 1 & 1 & 1 & 6 \\
\hline GENOVA & - & - & - & - & - & 1 & 1 \\
\hline GERONA & - & - & - & - & - & 2 & 2 \\
\hline$|B| Z A$ & 5 & 2 & - & - & 3 & 15 & 25 \\
\hline LISBOA & 2 & - & - & - & - & 2 & 4 \\
\hline LLANÇA & - & 1 & - & - & - & - & 1 \\
\hline MALLORCA & 99 & 53 & 18 & 34 & 24 & 112 & 340 \\
\hline MENORCA & 3 & 1 & - & - & - & - & 4 \\
\hline MONTPELLIER & - & - & - & - & - & 6 & 6 \\
\hline NARBONA & 1 & 1 & - & - & - & 5 & 7 \\
\hline PALAMOS & - & 1 & - & - & - & - & 1 \\
\hline PERPIÑAN & 2 & - & - & - & 1 & 8 & 11 \\
\hline PISA & - & - & - & - & - & 4 & 4 \\
\hline PORTUGAL & - & 2 & - & - & - & - & 2 \\
\hline ROSAS & 4 & - & - & 1 & - & 5 & 10 \\
\hline SANT FELIU & - & - & - & 1 & - & 5 & 6 \\
\hline SERINYA & - & - & - & - & - & 1 & 1 \\
\hline SEVILLA & 1 & - & - & - & - & 1 & 2 \\
\hline SIN ESPECIFICAR & 1 & 4 & - & - & - & 2 & 7 \\
\hline SU NAVE & 2 & - & - & - & - & 6 & 8 \\
\hline TARIFA & - & 1 & - & - & - & 7 & 8 \\
\hline TARRAGONA & 9 & 13 & 2 & 2 & - & 8 & 34 \\
\hline TORTOSA & - & - & - & - & - & 4 & 4 \\
\hline
\end{tabular}


En efecto, durante los siglos bajomedievales, ya desde la conquista, Valencia y Mallorca sostuvieron unas relaciones comerciales privilegiadas, tal como han puesto de relieve los estudios de F. Sevillano Colón, A. Santamaría, N, Bauzá, P. Macaire y otros $^{15}$. Estos contactos databan ya desde el reinado de Jaime I, y Sevillano recoge la noticia de un viaje que en 1240 hizo una nave mallorquina a Valencia, así como otros en años posteriores a los puertos de Denia, Alicante y Valencia ${ }^{16}$, prosiguiendo una tradición que se remontaría a la etapa musulmana y que no se interrumpió en los siglos medievales. El citado autor señala que hasta 1376 el comercio de Mallorca fue más intenso con Cataluña, en particular con Barcelona, que con otros lugares. Pero en el último cuarto de siglo cambió la trayectoria y el grueso de los contactos exteriores de Mallorca fue hacia los puertos valencianos.

Aventura la hipótesis de que esta canalización del tráfico hacia las costas valencianas estuviera relacionado con un incremento del tráfico hacia Almería, Málaga y puertos norteafricanos, que harían escala previamente en Valencia.

Entre 1321 y 1340, según datos del dret de l'ancoratge los buques valencianos llegados a Mallorca suponían entre el $20 \%$ y el $28 \%$. Las licencias de exportación o guiatges de salida desde Mallorca hacia Valencia en el periodo que estudiamos, el tercer cuarto de siglo oscilan entre el $16{ }^{\prime} 6 \%$ en 1359 y el $19 \%$ en 1377 con su cota máxima en 1374 , en que se alcanza el $32 \%{ }^{17}$.

Comparados estos datos con los que tenemos para la exportación valenciana de productos prohibidos a Mallorca tenemos:

\begin{tabular}{|lrrrrrr|}
\hline & 1351 & 1357 & 1359 & 1360 & 1364 & 1378 \\
\hline VIAJES POR MAR & 174 & 86 & 25 & 50 & 36 & 260 \\
A MALLORCA & 99 & 53 & 18 & 34 & 24 & 112 \\
PORCENTAJE & $56^{\prime} 8$ & 61 & 72 & 68 & 66 & 43 \\
\hline
\end{tabular}

Los porcentajes son lo suficientemente expresivos para que destaque la posición preeminente que Mallorca tenía como receptora de este tipo de mercancías. Los intercambios están controlados por los mercaderes mallorquines, casi igualados por los valencianos, y de forma esporádica por catalanes.

15 F. SEVILLANO COLOM y J. POU MUNTANER, Historia del puerto de Palma de Mallorca, Palma de Mallorca, 1974; A. SANTAMARIA, Aportación a la economía valenciana del siglo XV, Valencia, 1966; N. BAUZA, “El tràfic maritim amb les Balears a través d'un notari valencià del segle XV», Estudis Baleàrics, 9, 1983, pp. 27-56; P. MACAIRE, Majorque et le commerce international (1400-1450) environ, Lille, 1986; J. HINOJOSA MONTALVO, «El Consell valenciano y el reino de Mallorca durante el siglo XIV", XIII congrés d'Història de la Corona d'Aragó, Palma de Mallorca, 1989, Comunicacions I (primera part), pp. 85-98.

16 F. SEVILLANO, Historia del Puerto de Mallorca, p. 184.

17 F. SEVILLANO COLOM, "Mallorca y Valencia: relaciones marítimo-mercantiles en el siglo XIV", I Congreso de Historia del País Valencià, Valencia, 1980, II, pp. 542-550. 
La colonia mallorquina en Valencia era numerosa ya por entonces y sus actividades comerciales abarcaban todo tipo de productos. A veces actuaban a través de procuradores, y así vemos en 1357 a Bernat Planell «faedor» de Joan Rodrigo, de Mallorca, enviar a esta ciudad dos dobleras. $\mathrm{O}$ a domingo Corts, farmacéutico de Valencia, procurador de Guillem Pere, mercader mallorquín, que el 22 de marzo de 1362 reconocía ante el notario valenciano Ramón Bernat, que Fat Albarramoni, Mahomat Xupió y su madre Çofra, y Abrafim Ferrer, de Valencia, le pagaron 36 libras, de aquellas 75 por las que rescataron a Rahamona, esclava de Trípoli, del citado Guillem Pere. Ese mismo día el citado mercader concedía la libertad a la esclava ${ }^{18}$.

Algunos de estos mercaderes mantenían contactos regulares con Mallorca y los vemos negociando en años sucesivos, como Berenguer Vidal, de Valencia, documentado en 1357 y 1359 , o el judío valenciano Vidal Paci, que en 1378 realizó envíos regulares a Mallorca, por citar un par de ejemplos. No obstante, lo habitual en el manejo de este tipo de mercaderías eran las operaciones únicas por cada mercader.

No abundan las menciones de las embarcaciones utilizadas en este tráfico, citándose la barca y el leño, embarcaciones ligeras, rápidas, de tonelaje modesto, habituales en el cabotaje, sin que la documentación precise más. Mayor porte tenía la coca, de las que se mencionan una de Valencia y dos de Mallorca en 1351.

Mallorca enviaba a Valencia una serie de productos limitados: hojas de espada, ballestas, hierro, quesos, salazón de carnes (1360), quesos de Cerdeña (1361); cautivos sardos liberados, esclavos tártaros, búlgaros, griegos o de otras procedencias, ballestas y remos, hojas de espada (1371). Era frecuente importar madera de Mallorca, y en julio de 1374 los jurados de Valencia notifican a Olfo de Próxita, gobernador de Mallorca, y a los jurados de la capital, el comienzo de la construcción de dos galeras, de acuerdo con el rey, necesitando para ello mástiles, antenas y 400 remos, cuya compra se encargó a Guillem d'Uyll, de Mallorca ${ }^{19}$.

También tenemos el caso contrario, de mallorquines que vienen a aprovisionarse a Valencia. En 1338 el lugarteniente del reino de Mallorca comunicaba a los jurados de Valencia que el mallorquín Guillem Sala, junto con su socio Miquel Pellicer, de Valencia, tenían autorización para ir y comprar en Valencia madera, pez, estopa y cáñamo, sebo y otros artículos necesarios para la construcción de unas galeras en Mallorca.

Al igual que sucedió en Valencia, el tráfico marítimo de Mallorca comenzó a experimentar un notable incremento en 1376 y años posteriores, lo que se tradujo en unas exportaciones más diversificadas, que Sevillano Colom agrupa en artículos alimenticios: salazones de pescado, quesos de Mallorca y Sicilia, castañas, vino de la tierra, blanco, griego y calabrés; materiales industriales: hierro, áncoras, algodón, pez, jarcias y remos; armas: espadas ${ }^{20}$. A propósito del vino blanco de Mallorca, conviene recordar que en 1371 los jurados de Valencia autorizaron su entrada en la ciudad, a

18 A.R.V. Protocolos de Ramón Bernat, 2785.

19 ARCHIVO MUNICIPAL DE VALENCIA (A.M.V), Lletres misives, g3-3, fol. $34 \mathrm{r}$.

20 F. SEVILLANO COLOM, Mallorca y Valencia, p. 545. 
pesar de las ordenanzas locales que prohibián introducir vinos foráneos, aunque sólo podría ser regalado el vino mallorquín, pero no vendido ${ }^{21}$.

Tampoco los envíos desde Valencia a Mallorca presentan gran variedad de mercancías: algo de arroz y madera, a los que se añadirían otras materias primas, algunas manufacturas y alimentos en época de carestía. El arroz sólo lo hemos encontrado en tres viajes y en pequeñas cantidades. Más frecuentes son los envíos de madera semimanufacturada de diversos tipos: fusts serrats appellats dobleres, fusts appellats tirants, maderos, carratades, carratals, dobleres serrades, cabirons, todos ellos en madera de pino, que convertían a Mallorca en el primer puerto receptor de madera valenciana. Ocasionalmente se envía algún mueble (dos camas en 1359; ocho mesa de pinto y un arquibanco en 1378).

Otros productos manufacturados o semielaborados que se documentan en pequeñas partidas son: lanzas, dardos, hilo de cáñamo, etc. El grueso de las exportaciones lo integraban una serie de materias primas destinadas al consumo de la isla y a su reexportación: el sebo, cáñamo, acero, alquitrán, en cantidades no elevadas, y, sobre todo, pez y velas de sebo, como se puede apreciar en el siguiente cuadro:

\begin{tabular}{|lcc|}
\hline & 1351 & 1357 \\
\hline $\begin{array}{l}\text { Velas de sebo } \\
\text { Pez }\end{array}$ & $70,5 \mathrm{Qm} ; 33 \mathrm{rr} ; 39 \mathrm{Il}$. & $34,5 \mathrm{Qm}, 47,5 \mathrm{rr}, 21 \mathrm{II}$. \\
& $744 \mathrm{Qm}, 6 \mathrm{rr}$. & $222 \mathrm{Qm}$. \\
Velas & 1359 & 1360 \\
Pez & $10 \mathrm{Qm}, 14 \mathrm{rr}, 2 \mathrm{Il}$ & $5 \mathrm{Qm}, 11 \mathrm{rr}$. \\
& - & $27 \mathrm{Qm}$. \\
Velas & 1364 & 1379 \\
Pez & $25,5 \mathrm{Qm}, 16 \mathrm{rr}$ & $47 \mathrm{Qm}, 232 \mathrm{rr}, 167 \mathrm{I}$ \\
\hline
\end{tabular}

El descenso a partir de 1357 se vincularía a la guerra con Castilla y a las dificultades que para la navegación suponía la presencia de la flota castellana en aguas de la Corona de Aragón, ocasionando una recesión de los contactos mercantiles.

A las mercancías citadas se añadían en años de escasez el tráfico de productos alimenticios, favorecido por los jurados de ambas capitales con salvoconductos. En 1379, por ejemplo, se autorizaba a Domenec Civar, patrón de nave de Mallorca, y a Joan de Xarc, mercader de Valencia, a traer pescado arencado y salado desde MaIlorca para satisfacer las necesidades de Valencia durante la Cuaresma ${ }^{22}$. El abastecimiento de cereales era un asunto clave para ambos gobiernos municipales, dado que las dos capitales eran deficitarias en grano, de ahí que en torno al trigo girara buena parte de la correspondencia entre ambos municipios. En años difíciles, las autorida-

21 A.M.V. Manual de Consells, A-16, fol. 11 v.

22 A.M.V. Lletres misives, g3-4, fol. 62 r-v. Valencia, 21-2-1379. 
des de Mallorca pedían ayuda a sus colegas valencianos para que les enviaran alimentos, como hicieron desesperadamente en 1374, y aunque Valencia les envió algunas partidas de blats menuts y algarrobas, la situación en nuestro reino no era mucho mejor, y los jurados se excusaban de la ayuda que no podian prestar alegando la citada carestía, además de que "regularment caritat deja començar de si matexa» ${ }^{23}$. Para evitar las capturas de cargamentos de granos que desde Sicilia y otras regiones se dirigían a Mallorca y Valencia ambas capitales firmaron un pacto de mútuo respeto, en el que también se incluían Menorca e Ibiza ${ }^{24}$, aunque no pudieron evitar los episodios aislados de ataques a embarcaciones, por lo general valencianas, con las consiguientes protestas de sus autoridades.

La piratería de granadinos y norteafricanos, los corsarios castellanos o de la Corona de Aragón suponían un fuerte obstáculo para el desarrollo del comercio con normalidad, y los robos 0 asaltos de embarcaciones estaban a la orden del día ${ }^{25}$. Las autoridades trataron de ponerse de acuerdo para la defensa de los mares y costas contra los agresores, utilizando el sistema del pariatge entre Barcelona, Mallorca y Valencia, pero sin resultados positivos.

Los contactos mercantiles con Menorca e Ibiza fueron escasos en este tipo de productos prohibidos, sobre todo con la primera de las citadas islas. Con lbiza hay hasta un total de 25 viajes, iniciándose a partir de 1378 una etapa de crecimiento y estabilidad que se mantuvo el resto de la centuria ${ }^{26}$. A lbiza se enviaban velas de sebo $y$, en pequeñas cantidades, cáñamo, hierro, acero, plomo, lanzas, dardos, madera, estopa de cáñamo, en tanto que a Menorca van velas de sebo y dobleras. Son mercaderes de ambas islas los que despachan las mercancías desde Valencia.

\section{El área catalana}

Se configura como la segunda zona de interés para los productos valencianos, aunque lejos de las Baleares. En 1378, por ejemplo, si Mallorca absorbió 112 salidas, sólo 30 fueron a Barcelona, el primer puerto catalán de destino a partir de entonces.

La exportación de productos prohibidos valencianos hacia Cataluña abarcaba un amplio espectro geográfico como ya vimos, desde Tortosa al Rosellón, pequeñas localidades costeras comunicadas entre sí y con Valencia a través de una intensa navegación de cabotaje. Los más numerosos eran los puertos de la Costa Brava gerundense, manteniéndose esta trayectoria durante todo el Medievo. También la vía terrestre fue utilizada asíduamente para relacionarse con el Languedoc y el Midi galo, como demostró G. Romestan ${ }^{27}$. Recordemos que en 1333 Alfonso IV en una carta a los jura-

23 A.M.V. Manual de Consells, A-16, fol. $11 \mathrm{v}$.

24 J. HINOJOSA MONTALVO, El Consell valenciano y el reino de Mallorca, pp. 90-93.

25 A. DÍAZ BORRAS, Los origenes de la piratería islámica en Valencia, Barcelona, 1993.

26 R. FERRER NAVARRO, La exportación valenciana, p. 126. En 1381 son 18 asientos a lbiza, 10 en 1386, 29 en 1392, 26 en 1396 y 63 en 1399.

27 G. ROMESTAN, "L'activité des muletiers catalans entre Perpignan et Valence dans la première moitié du XIVe siècle», bulletin Philologique et Historique, Paris, 1969, 1, pp. 779-795. 
dos de Gerona les indicaba que no se debía exigir a los ciudadanos de Valencia que pasaban por aquella ciudad con sus mercaderías el derecho de pasaje, ya que iba contra lo estipulado ${ }^{28}$.

Pero estos intercambios de productos prohibidos, salvo unos cuantos puertos, no tuvieron relevancia hasta 1378 en que se observa la ya mencionada reactivación, en especial con Barcelona, que se colocó a la cabeza de lasz importaciones valencianas, con 30 asientos, seguida de Collioure con 21. Los trabajos de $\mathrm{Cl}$. Carrere pusieron de relieve cómo los catalanes buscaban en el reino de Valencia por entonces preferentemente materias primas: lanas, cueros y miel del Maestrat de Montesa; los cueros, seda, arroz, almendras, azúcar, lino, anís y otros productos agrarios de Valencia; a los que se añaden el esparto, la sal de La Mata, el trigo oriolano, los frutos secos, et. de Alicante, siendo los puertos preferidos de embarque los de Alicante, Denia, Valencia, Peñíscola y Castellón. A estos productos se añadirían diversas manufacturas típicamente valencianas como la cerámica, el papel, el hilo de seda, los cofres, etc ${ }^{29}$.

Collioure y Perpiñán son las plazas más activas en el Rosellón. Las relaciones con Collioure corrían a cargo de mercaderes de esta localidad, destacando en 1351 los de Valencia, Castelló d'Ampuries, Gerona, Narbona y Montpellier, que centralizaban en este puerto sus exportaciones hacia Valencia. En 1378 los mercaderes de Collioure eran los primeros, un total de nueve, frente a seis valencianos, dos de Narbona y uno de Perpiñán. A veces intervenían marineros de Barcelona, pues sabemos que en junio de 1335 naufragó en la playa de Burriana por causa del viento y del temporal el leño de Guillem Cata, de Barcelona, procedente de Colliure, cargado de hierro ${ }^{30}$. Burriana era también puerto de embarque hacia Collioure y en 1335 sabemos que Francesc Ambert, de Burriana, cargó varios leños, comisionado por Pere Vaquer, mercader de Castilla, con fruta, ropas y otras mercaderías hacia el puerto rosellonés ${ }^{31}$.

Los productos enviados desde Valencia eran pequeñas partidas de hilo de cáñamo, sebo, dobleras (1351), alquitrán desde Castellón, aunque eran la pez y las velas de sebo los artículos de mayor demanda:

PEZ

\begin{tabular}{|lccccc|}
\hline 1351 & 1357 & 1459 & 1360 & 1364 & 1378 \\
\hline $563 \mathrm{Qm}, 8 \mathrm{rr}$. & $120 \mathrm{Qm}$. & $140 \mathrm{Qm}$. & $24 \mathrm{Qm}$ & $15 \mathrm{Qm}$. & $63 \mathrm{Qm}$. \\
\hline
\end{tabular}

28 AUREUM OPUS privilegiorum civitatis et regni Valentiae, Lluís alanyà compilador. Valencia, 1515. Edición facsimil e índices por Mํ. D. CABANES PECOURT, Valencia, 1972, p. 244.

29 CL. CARRERE, Barcelona: 1380-1462. Un centre econòmic en época de crisi, Barcelona, 1977.

30 A.R.V. Bailia, 1152 bis, fol. 23 v. El baile general del reino escribió al de Burriana, ya que según Guillem de Rodes y Valentí Rosell, mercaderes de Valencia, el baile de esa localidad confiscó cierta cantidad de hierro que venía en dicho leño, consignada a ambos mercaderes. Se ordenó que se vendiera al mejor postor, entregando el importe a dichos mercaderes.

31 A.R.V. Bailia, 1142 bis, fol. 49 r. El cobrador de la lezda de Tortosa se quejaba de que se le debían ciertas sumas por dicho impuesto de estas mercancías. 
También en 1378 comenzó la reactivación del tráfico con Perpiñán, estando los intercambios en manos de mercaderes de esta plaza, adonde se enviaba sebo, arquibancos, pez y velas. Los valencianos por estas fechas seguían adquiriendo paños de Perpiñán y el 23 de abril de 1378 Pere Cardona, mercader de Valencia, fue condenado a pagar a Guillem Vela, mercader de Perpiñán, 20 libras, 7 sueldos y 6 dineros que le restaban por abonar por paños que le compró ${ }^{32}$. Este Guillem Vela envió ese año desde Valencia a Perpiñán velas de sebo. Los paños roselloneses estaban bastante difundidos por todo el reino y el 13 de agosto de 1378 Bernat Aimar, pañero de Alzira, se comprometió a pagar a Castelló Portell, mercader de Perpiñán, 500 sueldos que le había prestado para pagar una deuda de 81 libras con Bernat Figueres, mercader de Perpiñán, por cinco paños que le compró ${ }^{33}$.

Descendiendo por el litoral catalán encontramos una constelación de pequeños puertos, salida natural hacia el mar de las comarcas gerundenses del interior: Roses, Llansà, Palamós, Sant Feliu de Guíxols, Castelló d’Ampuries, Blanes, etc., hacia donde Valencia envió diversas cantidades de sebo, dobleras, pez -el artículo más solicitado-, cuerdas de cáñamo para la navegación. La propia Gerona mantuvo intensos contactos con Valencia pues en 1356 se fundó aquí una cofradía dedicada a Sant Narcís auspiciada por los mercaderes gerundenses establecidos en Valencia.

Barcelona se interesó poco por los productos vedados valencianos hasta 1378 , pasando a partir de ahora a ser el primer receptor de este tipo de mercaderías valencianas, tendencia que se mantuvo el resto de la centuria. Este tráfico se lo repartían casi a partes iguales una docena de mercaderes de Valencia y otra de Barcelona, que enviaban velas de sebo y pez.

La tercera zona catalana relacionada con Valencia era la de Tarragona y Tortosa. Con Tarragona los contactos mantuvieron una cierta regularidad, con un fuerte descenso a partir de 1359, y sólo en 1378 empieza la recuperación hasta aproximarse al nivel de 1351. En 1381 eran ya 27 los viajes anuales a Tarragona. La guerra con Castilla, tan activa en estos mares, retrajo el comercio. Los mercaderes valencianos y, en menor medida, los de Tarragona son los que cubrían dicha ruta, por donde circulaban las velas de sebo, pez ( $88 \mathrm{Tm}$. en 1351 , lo que supone el $5,5 \%$ del total) y madera en 1357 (41 maderos, 26 dobleras y 3 maderos serrados).

Tortosa aparece como puerto de destino de este tráfico en 1378, y durante el resto de la centuria mantuvo un tráfico muy irregular, de escaso volumen, en el que se incluían hierros para dardos, estopa, velas de sebo. Los puertos del norte valenciano también se relacionaban con Tortosa, favorecidos por su proximidad, y en 1334 vemos a vecinos de Tortosa sacando vino de Alcalà de Xivert ${ }^{34}$ por el cargador de Alcoceber, mientras que Peñíscola era el punto de embarque de las lanas valencianas y aragonesas ${ }^{35}$.

32 A.R.V. Justicia civil, 387, sin foliar.

33 A.R.V. Justicia civil, 387, sin foliar.

34 A.R.V. Bailia, 1152 bis, fol. 43 r.

35 A.R.V. Bailia, 1143, fol. 6 r. 
Los envíos de productos vedados hacia la península e islas italianas son tardíos, apareciendo en 1378, y muy reducidos, tanto en el marco geográfico como en el volumen del tráfico. Tan sólo Cagliari, Pisa y Génova reciben estos artículos. A Pisa son 4 salidas, a cargo de Bertomeu Borrell, Sanxo de Montagut, ambos valencianos, y micer Jacobo Boni, italiano, quizá pisano o genovés. Se exporta pez y velas de sebo. A Génova se llevó Joan Garro, mercader de Barcelona, 7 arrobas de velas, mientras que Jordi Lebres, de Valencia envió un quintal a Cagliari.

Estos contactos insignificantes muestran que Valencia tenía poco atractivo para los italianos en estos productos, tendencia que se mantuvo, -aunque al alza-, en años posteriores, al menos hasta 1397, en el que el porcentaje de las exportaciones hacia Italia creció de forma notable ${ }^{36}$. En los años estudiados Valencia se había insertado plenamente en el tráfico comercial y financiero con Italia, en el que la lana y la seda, los tejidos italianos y los tintes crearon un fuerte entramado de intereses que benefició a Valencia y a sus mercaderes, activos partícipes en estas empresas.

Este menguado tráfico dé coses vedades como decimos no refleja la realidad de los intercambios entre Valencia e Italia, que eran de mayor envergadura. Ya desde lá conquista de Valencia los mercaderes italianos se documentan en esta plaza, siguiendo una tradición que se remontaba a la etapa musulmana ${ }^{37}$. El abastecimiento de los ejércitos en las campañas de conquista y de los repobladores, el tráfico de esclavos, etc. crearon vínculos comerciales con Génova y Pisa, a los que se sumaron Florencia y otras ciudades italianas, aunque no es el objetivo del trabajo analizar la presencia italiana en el reino de Valencia en este siglo. Aunque la información más completa es para el siglo $\mathrm{XV}^{38}$, todavía siguen siendo en comparación escasas y dispersas las noticias para los dos siglos precedentes.

36 R. FERRER NAVARRO, La exportación valenciana, p. 145. En 1381 el número de asientos con productos prohibidos salidos desde Valencia fueron 482, de ellos 10 a Italia (2,07\%). En 1392 totalizó 502 asientos, de los cuales 18 a Italia $(2,7 \%)$, y en 1399 de 780 y 65 , respectivamente, lo que supuso el $8,3 \%$ del total.

37 M․ T. FERRER I MALLOL, "Els italians a terres catalanes (segles XII-XV)», Anuario de Estudios Medievales, 10, 1980, pp. 428-431 y 448-449; D. IGUAL y G. NAVARRO, Las relaciones económicas entre Valencia e Italia, analizan la presencia italiana en Valencia en los siglos XII y XIII, con un comercio centrado en Valencia y con extensiones hasta Denia y Peñíscola, controlado por italianos y basado en el comercio de esclavos, en la exportación de cereales y en la importación de paños, que crearon una comunidad de intereses entre Valencia y las repúblicas mercantiles italianas.

38 A los autores citados en notas anteriores habría que añadir: FURIO, A. (edit.), Valencia, un mercat medieval, Valencia, 1985; J. HINOJOSA MONTALVO, "Las relaciones comerciales entre Valencia e Italia durante el reinado de Alfonso el Magnánimo», Estudios de Edad Media de la Corona de Aragón, X (1975), pp. 439-512; "Sobre mercaderes extrapeninsulares en la Valencia del siglo XV», Saitabi, XXVI (1976), pp. 59-92; G. CONIGLIO, «Rapporti tra il regno di Valencia e Napoli nel secolo XV", Primer Congreso de Historia dle Pais Valenciano, Valencia, 1980, II, pp. 739-747; P. LÓPEZ ELUM, «El acuerdo comercial de la Corona de Aragón con los italianos en 1403. Dret italià", Ligarzas, 7 , Valencia, 1975, pp. 171-212; D. IGUAL, «Valencia y Sevilla en el sistema económico genovés de finales del siglo XV», Revista d'Història Medieval, 3, Valencia, 1992, pp. 79-116. 
Las buenas relaciones comerciales prevalecieron entre Aragón y las potencias italianas durante el siglo XIII, tras la conquista de Valencia, y una serie de privilegios y exenciones fiscales potenciaron los intercambios mercantiles. Pero tales favores de la monarquía despertaron el recelo y el descontento de los mercaderes locales ante lo que consideraban una competencia desleal y amenazadora, y exigieron a los reyes medidas proteccionistas, a la vez que comenzaron los decretos de expulsión contra los italianos, ya desde Jaime $1^{39}$.

En Valencia no conocemos expulsiones de italianos para el siglo XIII similares a las de Barcelona en 1265 o en 1269 en Mallorca, posiblemente porque eran pocos y no amenazaban la economía valenciana. En el decreto de 15 de marzo de 1326 por el que se expulsaba a los lombardos, florentinos, toscanos, luqueses, sieneses y otros italianos de Valencia y se les prohibe residir en la capital, Jaime II alegaba dos razones: la desigualdad contributiva, que hacía que los italianos estuvieran exentos de imposiciones locales, lo que redundaba en la mejor marcha de los negocios; por otra parte, las prácticas monopolísticas de los italianos, acaparando las mercancías perjudicaban a los comerciantes locales, cuya debil situación se hubiera visto amenazada con la instalación de compañías financieras toscanas ${ }^{40}$. Los florentinos disponían de importantes capitales y los Bardi, los Peruzzi o los Acciaiuvoli, las tres grandes compañías de Florencia por excelencia, ponían su dinero a disposición del monarca o de las instituciones, como por ejemplo la sede valenciana. Así del 6 de octubre de 1301 se conserva una cesión de crédito otorgada por una sociedad italiana de las cantidades que le debían los obispos de Valencia, Andreu Albalat y Jazperto de Botonach ${ }^{41}$. Parte del dinero recaudado por Alfonso IV en Valencia como contribución a la cruzada granadina fue destinado a cancelar las deudas contraidas por la Corona con los Peruzzi en 1342, 1325 y 1327 durante la campaña de Cerdeña $a^{42}$, y entre 1330-1332 el factor de la mencionada compañía en Barcelona y en Valencia debió residir en esta última plaza.

Los monarcas, aunque con vacilaciones, procuraban atender las peticiones de sus súbditos, y la tensión bélica entre Aragón y Génova hizo crecer la xenofobia contra los italianos, y en 1332 Alfonso IV extendía a todo el reino de Valencia el privilegio de 1326, justificándolo en términos morales por los fraudes cometidos por dichos mercaderes. No se incluían los genoveses ni Córcega, Cerdeña o Sicilia, vinculadas a la

39 Puede verse todo el proceso con detalle en la obra ya citada de M․ T. FERRER I MALLOL, Els italians, p. 394 y ss.

$40 \mathrm{M}^{\mathrm{a}}$ T. FERRER I MALLOL, Els italians, p. 397. A.R.V. Real, 659, fol. 195 r. bis.; M. SÁNCHEZ MARTÍNEZ, "Operaciones de los Peruzzi y los Acciaiuvoli en la Corona de Aragón durante el primer tercio del siglo XIV", Anuario de Estudios Medievales, 7, 1970-71, pp. 285-311; D. IGUAL y G. NAVA$\mathrm{RRO}$, Las relaciones económicas. analizan estas operaciones financieras de las compañías florentinas, así como su interés por el mercado del dinero a través de los instrumenta ex causa cambii.

41 E. OlmOS CANALDA, Pergaminos de la catedral de Valencia, Valencia, 1961, p. 795.

42 M. SÁNCHEZ MARTÍNEZ, "La contribución valenciana a la cruzada granadina de Alfonso IV", I Congreso de Historia del País Valenciano, Valencia, 1980, II, pp. 579-598. 
Corona de Aragón. Estas expulsiones, junto con el aumento de las cargas impositivas y la piratería hizo que apenas hubiera ligures en Valencia.

Como señala $\mathrm{M}^{\mathrm{a}}$. T. Ferrer i Mallol en el resto de la centuria asistimos a un incremento de la presencia italiana en nuestras tierras, a una política de la monarquía más liberal, que se verá salpicada por diversos incidentes y expulsiones a tenor de las situaciones de guerra $u$ otras tensiones ${ }^{43}$. Las expulsiones o la revocación de licencias para comerciar, como en 1368, originaban tensiones entre el gobierno municipal y el real, como sucedió en 1372 cuando el baile de Valencia, a instancias del rey apresó a todos los mercaderes genoveses en Valencia, confiscando sus bienes, mercancías y barcos, lo que provocó la protesta de los jurados al rey en defensa de los genoveses, que estaban guiados por el municipio en razón del trigo y otros alimentos que habían traido. La política anti-italiana prosiguió en reinados sucesivos, con suerte alterna, debido a los múltiples factores en juego, desde la política real a la del Consell y los mercaderes, pasando por los propios afectados, los italianos, con intereses a menudo contrapuestos. De hecho, la repetición de las medidas de expulsión revelan su ineficacia e incumplimiento general.

En los años estudiados se detecta la presencia en Valencia de genoveses, pisanos y luqueses. Ya en junio de 1149 Génova concluía un acuerdo con el rey de Valencia, Boabdil Mahomat, hijo del "rey Lobo", por el que obtenía un tributo de 10.000 morabatinos, un fóndaco en exclusiva en la ciudad y otro en Denia, así como la exención de tributos en las tierras del soberano musulmán ventajas excepcionales que los genoveses conservaron en buena medida en los siglos posteriores, cuando estas tieras pasaron a soberanía aragonesa. Tras la conquista los genoveses siguieron comerciando con Valencia, y los contactos comerciales, de los que tenemos noticias aisladas ${ }^{44}$, fueron en aumento durante este siglo y buena parte del XIV gracias a las buenas relaciones mantenidas hasta la conquista de Cerdeña, que trajo la ruptura con Pisa y Génova. Desde entonces la guerra y las buenas relaciones alternaron, con el consiguiente quebranto que ello ocasionaba a los mercaderes, que veían sus vidas y haciendas expuestas a las represalias, cancelación de viajes, confiscaciones, prisión, etc. como la ya citada de 1372, repetida en 1383 por la ayuda que los genoveses prestaban a los rebeldes sardos.

En Valencia, aunque los genoveses no tuvieron en estas fechas la importancia que alcanzaron en Barcelona o la que gozarían en la ciudad del Turia en la segunda mitad del siglo XV, comenzaron a ser cada día más numerosos, sin duda la principal colonia de operadores italianos, cuya presencia está impulsada por la libertad de comercio, que nadie les discute, por las exenciones fiscales que se retrotraen al siglo XIII, y que en todo momento defendieron encarnizadamente, como por ejemplo cuando en 1402 Martín el Humano dispuso la creación de la nueva tasa conocida como dret dels italians ${ }^{45}$.

$43 \mathrm{M}^{\mathrm{a}} \mathrm{T}$. FERRER I MALLOL, Els italians, pp. $400 \mathrm{y}$ ss.

$44 \mathrm{M}^{a}$. T. FERRER I MALLOL, E/s italians, p. 435 y las notas 171 y 178.

45 P. LÓPEZ ELUM, El acuerdo comercial de la Corona de Aragón; Ma․ T. FERRER I MALLOL, Els italians, p. 409. 
Hasta 1378 son escasas las menciones de genoveses en Valencia, siendo la lana uno de los artículos más buscados por estos mercaderes, y en 1370 se documenta a Francesc Ivars, mercader de Génova, (el apellido sugiere un catalanoparlante nacionalizado genovés) que adquirió a Lluís de Calatayud, caballero gobernador del marqués de Villena, y a Pere Joan, ciudadano de Valencia, mil arrobas de lana, a 31 sueldos la arroba, que le sería entregada en el marquesado de Villena. El pago fue de 500 florines de Mallorca al contado y el resto el 10 de abril. El 11 de abril compraba otras 400 arrobas de lana aragonesa a Joan Llorens, pelaire de Valencia, que sería depositada en la casa del genovés Ivars se documenta en 1380 y el 6 de julio nombraba procurador a Bertomeu Martí, mercader de Mallorca, para recuperar 108 libras, 3 sueldos y 5 dineros que le debía Joan Terés, farmacéutico de Valencia, por dos cargas, 14 libras y 9 onzas de papel que le vendió. El día 7 Ivars e Inoficius de Aniyolo, genoveses, nombraban procurador a Bertomeu Barós, también genovés, para recuperar de Joan Cortés, farmacéutico valenciano, 108 libras, 3 sueldos y 5 dineros por 2 cargas, 11 libras y 9 onzas de papel que le vendieron. El negocio aparecía centrado en la compra de materias primas valencianas o de los reinos vecinos, sobre todo la lana, a cambio de manufacturas italianas, entre ellas el papel. La expulsión de 1372 no influyó negativamente en el comercio con Génova, y suscitó las dudas en los ánimos de muchos mercaderes a la hora de aventurarse a comerciar con Valencia. El 7 de abril de 1375 los jurados de Valencia recordaban a micer Giner Rabasa, menor, su compromiso de resolver la duda planteada por un mercader genovés sobre el respeto por el baile general de los guiajes concedidos por los jurados a los que traían vituallas, dilación que perjudicaba al genovés.

La firma de las paces entre Aragón y Génova hizo que se reanimara el comercio y el 15 de diciembre de 1378 los jurados valencianos notificaban a los de Peñíscola, a ruegos de micer Nicoloso de Mar, genovés residente en Valencia, que los genoveses que aquí negociaban estaban exentos del pago de impuestos a las mercancías que compraran o vendieran, y otro tanto los súbditos del rey de Aragón en Génova ${ }^{46}$. A partir de ahora comienzan a aparecer más noticias de genoveses en Valencia, como los hermanos Pedro y Jorge Barós, que vendían pastel a diversos tintoreros valencianos $^{47}$. También el genovés Bartolomeo del Pozo y Agostino Osbraguer negociaban ese año con pastel ${ }^{48}$. Los Barós estaban ya en Valencia en 1377, pues el 14 de diciembre Pedro nombró procurador suyo a su hermano Jorge, poder que le revocó el 30 de diciembre de $1379^{49}$.

Los otros mercaderes genoveses documentados en 1379 y 1380 son el ya mencionado Nicoloso de Mar, que debía gozar de una cierta autoridad moral por cuanto le vemos intercediendo ante los jurados de Valencia en 1378 por sus conciudadanos, y

46 A.H.M. Lletres misives, g3-4, fol. $50 \mathrm{v}$.

47 A.R.V. Justicia civil, 387, sin fol. Valencia, 26-5-1378.

48 A.R.V. Justicia civil, 387, sin fol. Valencia 16-11-1378. Vicent Xullella, mercader de Valencia, le debe 17 libras, 14 sueldos, 6 dineros por tres sacos de pastel.

49 A.R.V. Protocolos notariales de Guillem Vallseguer, 2772. 
en 1379 la viuda de Salvador de Ravanera, cambista de Valencia, lo nombró su procurador para que recuperara 39 libras que le debía a su esposo Abeyda de Mar, genovés ${ }^{50}$.

Batista de Riso residía en Valencia en 1380 y el 10 de julio nombraba procurador suyo a Bertomeu de la Càrrega, mercader de Valencia, para recuperar cualquier deuda pendiente ${ }^{51}$, en tanto que el notario Pere Clariana se comprometía a pagarle 15 libras que le debía en el plazo de cinco meses ${ }^{52}$. Sabemos que Bertolino Descartis, abogado de Génova, le debía 20 libras genovesas y que se las remitiría a través de Antonio Riso, hermano de Batista ${ }^{53}$.

En algún caso los vemos dedicados a vender esclavos, como Ofio de Avinyes, genovés, que vendió a Macià Martí, tundidor de Valencia, un esclavo tártaro por 30 libras ${ }^{54}$, o de papel, como los ya citados Francesco Ivars o Bartolomeo Barós, que en 1380 vendieron papel a Joan Terés, farmacéutico.

Otras veces intervenían en asuntos monetarios, como Pietro de Bonifacio, genovés, que tenían en comanda de Ferrando de Fraschi, genovés, 50 florines que le había enviado, y que le devolvería en Génova ${ }^{55}$, mientras que Cristiani Catani, genovés, debía a Rodrigo Gonzálvez, criado de Pedro Farina, mercader de Bayona del Miño, 632 doblas castellanas cruzadas de oro fino, por un cambio que le envió a Valencia de 600 libras, 12 sueldos, a razón de 19 sueldos por cada dobla. El pagó sería en Sevilla a través de Catani Gentilib6. El 21 de noviembre de 1380 actuaba como testigo de Opiso Pagani, de Luca, en una cancelación de deuda.

Sin embargo, las relaciones con Génova eran un tanto tensas. En 1379 los mercaderes valencianos en Génova eran discriminados con relación a los de Mallorca y Barcelona, y se les obligaba a abonar todos los derechos, en particular la gabela del vino, como respuesta a la captura de una nave genovesa en Alghero. Se rumoreaba que cualquier día los valencianos podrían ser expulsados de la ciudad ligur, medida que resultaría particularmente dañina, por cuanto que la mayoría de las mercancías que van a Génova - se decía- salen de Valencia. Este testimonio de los jurados valencianos en la carta que enviaron el 24 de noviembre a Francesc Urgellés, mensajero ante el rey, testimonia la importancia que por entonces tenian ya los intercambios entre Valencia y Génova. Los valencianos en Génova no consiguieron hacer oir su voz ante el duque y los doce ancianos del Consejo, ni tampoco tuvieron efecto positivo las cartas de los jurados, por lo que se pensó en revocar los privilegios que los genoveses tenían en Valencia, pero los jurados no se atrevían a hacerlo sin el consentimiento del

50 A.R.V. Protocolos notariales de Guillem Almudéver, 3017, Valencia 21-4-1379.

51 A.R.V. Protocolos notariales de Bernat Costa, 633. sin fol. Valencia, 10-7-1380.

52 A.R.V. Protocolos notariales de Bernat Costa, 633, Valencia, 17-7-1380.

53 A.R.V. Protocolos notariales, 633, sin fol. Valencia. 30-4-1380.

54 A.R.V. Protocolos notariales de Bernat Costa, 633, sin fol. Valencia. 17-7-1380.

55 A.R.V. Protocolos notariales de Bernat Costa, 633, sin fol. Valencia, 16-10-1380.

56 A.R.V. Protocolos notariales de Bernat Costa, 633, sin fol. Valencia, 27-9-1380. 
rey, al no conocer el texto de las paces existentes entre Aragón y Génova, por lo que se pedía la intervención ante las autoridades genovesas en favor de los valencianos ${ }^{57}$.

Los pisanos aparecen ya en el siglo XIII y, como los genoveses, tenían sus relaciones con Aragón reguladas por pactos bilaterales, por lo que las expulsiones decretadas contra los italianos en general no debieron afectarles. En 1279 aparecen especializados en el transporte de armas entre Valencia y Castilla, y el 4 de mayo el monarca autorizaba a unos lorigueros pisanos a llevarse a Castilla desde Valencia armaduras, lorigas, espadas, clavos, etc, y poder venderlos según los precios indicados. Un permiso similar se dió el 13 de febrero al pisano Febo $^{58}$. En 1343 se documenta en Valencia al mercader pisano Matteo Picalcani, contra el que se ejecutó un derecho de marca pendiente contra pisanos ${ }^{59}$. En 1379 se firmó una paz entre Aragón y Pisa, y en 1380 Joan de Soyana, mercader de Pisa, reconocía que tenía del luqués Opiso Pagani 100 libras $^{60}$.

Esporádicamente aparecen por estas fechas mercaderes de otras ciudades toscanas, como Luca, de donde procedía el ya citado Opiso Pagani, a quien vemos en 1378 comerciando con Agde, y en 1380 como factor de Andrea de Taxi, cambista, negociando letras de cambio en su nombre. Vivía en una casa alquilada a Francesc Franc en el Mercat de Valencia ${ }^{61}$. Respecto a lombardos y venecianos no hemos detectado su presencia en Valencia en estos años, y habrá que esperar a finales de la centuria para tener noticias seguras de estos intercambios ${ }^{62}$.

Con Francia el comercio marítimo valenciano tenía sus principales destinos en el área del golfo de Lyon, en el Languedoc: Aigües-Mortes, durante mucho tiempo -hasta el siglo XV- el único puerto mediterráneo de la corona francesa ${ }^{63}$, sólo muestra una salida en 1351, en que Bernat Ballester, de Valencia, se llevó 3 quintales de velas de sevo. A Agde hay algunos envíos esporádicos de pez, alquitrán o velas de sebo en 1359,1360 y 1378 .

En 1378 aumentó el número de puertos con los que Valencia mantiene relaciones, y así vemos dos embarques hacia Avignon por Huc Bonanat, de Mallorca, y Jaume Descamos, párroco de Moncada, que se llevó velas. La presencia de la corte papal en

57 A.M.V. Lletres misives, g3-4, fol. 124 v-125 r. Valencia, 24-11-1379.

58 J.M MaRTÍNEZ FERRANDO, Archivo de la Corona de Aragón: catálogo de la documentación relativa al antiguo reino de Valencia contenida en los registros de la cancillería real. Vol. I. Jaime I, Vol. II. Pedro el Grande, Madrid, 1934. II, doc. 388 y 846.

$59 \mathrm{M}^{\mathrm{a}}$.T FERRER I MALLOL, Els italians, p. 451

60 A.R.V. Protocolos notariales de Bernat costa, 633. Valencia 21-11-1380.

61 A.R.V. Protocolos notariales de Bernat Costa, 633, Valencia, 21-11-1380.

62 En 1397 aparece un asiento con productos vedados a Venecia, y en 1398 son seis. R. FERRER NAVARRO, La exportación valenciana, p. 129. Ma.T. FERRER I MALLOL, Els italians, pp. 463-464 menciona a Bernardo Bo, instalado en Valencia antes de 1399; también residían Francisco Serraner, Andrea Cornaro y quizá Moret Bergadim, todos ellos venecianos.

63 G. GEHEL, "Les conditions techniques de l'installation d'un établissement portuaire en Méditerranée: l'exemple d'Aigues-Mortes», Città portuali del Mediterraneo. Storia e archeologia, Genova, Sagep, 1989, pp. 203-212. 
la ciudad del Ródano explicaría este viaje de un clérigo valenciano. Hacia Beziers salió una partida de 7 arrobas de velas, enviadas por Jaume Scaler.

Pero serían Narbona y Montpellier los puertos más activos en el tráfico de productos prohibidos, aunque siempre en pequeñas partidas, por lo que no podemos precisar la auténtica naturaleza de los intercambios comerciales entre Valencia y estas plazas. Con Narbona había una vieja e intensa relación comercial, que Guy Romestan estudió en profundidad para la primera mitad de siglo, resaltando el papel de los mercaderes narboneses en el tráfico de productos textiles languedocianos hacia Valencia y Castilla, mientras que Valencia exportaría a Narbona pez, alquitrán, sebo, jabón y otros productos exóticos, en una economía que calificó de «colonial». Pero desde 1340 el papel de los narboneses en el comercio valenciano entró en decadencia a causa de la competencia de los mercaderes y paños valencianos. Los datos que aportamos son, por el momento, modestos, pero contribuyen a llenar esta laguna en las actividades mercantiles en estos años. Vemos cómo el tráfico marítimo hacia Narbona se equilibra entre valencianos y narboneses, siendo las velas de sebo y el sebo el objeto de las exportaciones. En 1380 residía en Valencia el narbonés Bernat Restany, que el 5 de enero reconocía deber a fray Jaume de Sant Martí, vicario de Santa María del Puig, 25 florines que le había prestado ${ }^{64}$.

Montpellier era también para los valencianos un centro de aprovisionamiento de paños locales o del Norte y allí acudían a efectuar sus compras, mientras que mercaderes de Montpellier vendían en Valencia en 1317 paños de Ypres, Flandes o de la región parisina ${ }^{65}$. En el marco de los productos prohibidos hasta 1378 no aparece esta ciudad del Midi, siendo mercaderes valencianos los que monopolizaban el tráfico ${ }^{66}$, a los que se añade un estudiante, Andreu Martí, que desde Valencia fue a la prestigiosa universidad de Montpellier a estudiar. Pero el balance de estos intercambios con productos vedados apenas merecería nuestra atención: tan sólo 17 arrobas de velas.

Además de este comercio marítimo con el Mediodía francés, Valencia mantuvo relaciones comerciales con el resto de Francia, pero de momento se nos escapa su magnitud, debido a lo escaso y disperso de las fuentes. Lo cierto es que los mercaderes valencianos llegaban hasta el corazón de Francia, como testimonia la marca decretada por el rey de Francia en 1333 contra todos los súbditos del rey de Aragón, a consecuencia del pleito entre Guillem de Bones Mans, francés, y Pere de Migavila, mercader de Valencia. La represalia mercantil afectaba a los valencianos que tenían mercancías en Francia, que les fueron confiscadas en París y en otras localidades. Parece que la tensión en estas relaciones prosiguió en años posteriores, y en 1341 los jurados de Valencia decidieron, igual que hizo Barcelona, enviar un embajador al rey francés para pedirle que anulara el derecho de marca otorgado a Bernat de Mallach y Esteve Roger contra mercaderes franceses. Tal medida era lógico que provocara un retraimiento de los intercambios y para el patriciado que gobernaba la ciudad era

64 A.R.V. Protocolos notariales de Bernat Costa, 633. Valencia, 5-1-1380.

65 F. ROMESTAN, Les marchands languedociens, p. 194.

66 Se documentan a Joan Angeles, Francesc Martorell, Miquel Palomar y Joan Costra. 
negativo para sus intereses comerciales, de acuerdo con sus esquemas mentales y su programa de gobierno.

Mediados los años setenta detectamos la presencia de marinos y mercaderes del noroeste de Francia. En 1374, por ejemplo, los jurados notificaban a los patrones de galeras de la ciudad, la concesión de un guiaje a Raunet de Bellaflor, patrón de SaintMalo, que se había comprometido a traer de Bretaña o de Normandía una carga de trigo, asegurada por los jurados ${ }^{67}$. La penuria de granos, una realidad frecuente en la Valencia del siglo XIV ${ }^{68}$, se agravó con las fuerte carestía de 1374-75, que obligó a las autoridades a buscar cereales por doquier, incluyendo las lejanas tierras normandas y bretonas. En 1380 noegociaba en Valencia Jean de Pietro, mercader bretón, de Nantes, que nombró procurador suyo a Opiso Pagani para contratar en su nombre cualquier tipo de mercaderías y cambios que le llegaran por tierra o por mar ${ }^{69}$. El apellido Pietro parece sugerir un italiano afincado y avecindado en Bretaña, lo que explicaría sus vinculaciones con el luqués Pagani.

\section{Los países musulmanes}

Continuando en el área mediterránea hay que constatar la ausencia durante estos años de intercambios de productos vedados entre Valencia y el Norte de Africa y Granada, en buena parte relacionadas con las dificultades que para la navegación representaba la guerra de los dos Pedros,entre Aragón y Castilla, relaciones que ya desde 1381 aparecen con regularidad ${ }^{70}$. Pero estos intercambios eran sólo una parte de la realidad comercial, más rica y compleja. Ch. E. Dufourcq resume en estas las características de este comercio de la Corona de Aragón con el Maghreb71:

1 - Deseo catalán de adquirir productos africanos.

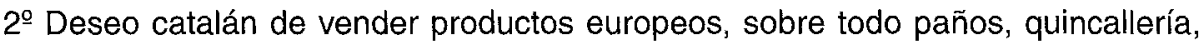
alimentos, armas y metales.

$3^{\circ}$ Comercio servil: compra y rescate de esclavos; corso.

$4^{\circ}$ Continuidad casi absoluta de este comercio entre los siglos XIII y XV, a pesar de las prohibiciones.

$5^{\circ}$ Vitalidad de las colonias catalanas en tierra magrebí.

6ํㅡㄹ Flexibilidad de la política real, con múltiples objetivos: favorecer el comercio, obtener ventajas financieras para la Corona, etc.

67 A.R.V. Letres misives, $93-3$, fol. $119 \mathrm{v}$.

68 A. RUBIO, "Crisis agrarias y carestías en las primeras décadas del siglo XIV. El caso de Valencia», Saitabi, XXXVII, 1987, pp. 131-147.

69 A.R.V. Protocolos notariales de Bernat Costa, 633, Valencia, 24-1-1380.

70 A Berbería entre 1381 y 1399 salieron desde el Grau de Valencia 76 asientos con coses vedades. R. FERRER NAVARRO, La exportación valenciana, p. 129.

$71 \mathrm{CH}$. E. DUFOURCQ, «Liasons maritimes et commerce catalans, majorquins et valenciens avec le Maghrib, du XUUUe au XVe siècles", La península ibérica y el Mediterráneo centro-occidental", Barcelona-Roma, 1980, pp. 111-112. 
La falta de fuentes impide conocer por el momento con precisión estos intercambios desde Valencia, pero algunas de las conservadas ponen de manifiesto las activas relaciones mantenidas con Berbería, en particular con el área argelina, siendo Argel y Orán los principales puertos. A través de los salvoconductos concedidos por el baile general del reino vemos a numerosos moros de Valencia: Yátova, Xàtiva, la montaña alicantina (Benidoleig, Murla, Jalón, Ondara, Parcent, Vall de Laguar, Pedreguer, etc.), que van a Berbería y Almería a comerciar, en 1335.

El transporte se realizaba en embarcaciones valencianas, siendo el leño la única embarcación mencionada. Las mercancías se engloban bajo el genérico "robes $e$ mercaderies" y tan sólo en un par de ocasiones se menciona productos específicos: los higos. Por supuesto, no faltarían los paños, productos del agro valenciano, metales, etc. pero sin que podamos precisarlo. Los moros de señorío laico necesitaban permiso de su señor, previo a la licencia del baile general, y así vemos como en 1335 Vicent Solà, mercader de Valencia y señor de la alquería de Canor, en el término de Calpe, atestigua que Ahmet Alhami, vasallo suyo, tenía la correspondiente licencia para ir a comerciar a Berbería ${ }^{72}$.

A veces se formaban compañías mercantiles mixtas entre cristiano y moro para comerciar con el Norte de África, como la que establecieron Pere Vinyals, mercader de Valencia, y Azmet Al-Roig y Alí Albarramoni, de Valencia, que el 20 de enero de 1380 rindieron cuentas ante notario sobre una comanda de trigo que Albarramoni recibió de Vinyals en Honein para llevarlo a Ceuta y sobre otros negocios realizados por dicha compañía ${ }^{73}$. Este Albarramoni sería uno de los mercaderes más activos de la morería valenciana por aquellas fechas.

Los contactos entre Valencia y Ceuta debieron ser raros, aunque sabemos que los mercaderes de la Corona de Aragón vendían en esta plaza trigo, vino, naranjas, frutos secos, miel, lana, cerámica, esclavos, telas, etc. a cambio de algodón, hierro, aceite, pieles, etc. ${ }^{74}$.

En el reino nazarí de Granada, que tuvo fuertes relaciones comerciales con Valencia, era Almería el principal foco de destino ${ }^{75}$ de los mercaderes musulmanes valencianos. En los guiajes no se mencionan los productos, pero cabe pensar en los paños y los productos del agro valenciano a cambio de la seda y artículos africanos como principales mercancías de intercambio. En 1374 las relaciones atravesaron un mal momento. El noble Francés de Perellós, a su regreso de Burdeos, donde se habia entrevistado con el duque de Lancaster, fue apresado en las costas andaluzas por

72 A.R.V. Bailia, 1142 bis, fol. 12 r.

73 A.R.V. Protocolos notariales, 2772, sin fol. Valencia, 20-1-1380.

74 R. AMRAN COHEN, Ceuta y el mundo mediterráneo durante los siglos XII y XIII, Ceuta, s. f; «Acercamiento a la historia económica de Ceuta. Siglos XII y XIII», Congreso Internacional. El Estrecho de Gibraltar, Ceuta, 1987, pp. 221-230.

75 J. HINOJOSA MONTALVO, "Las relaciones entre los reinos de Valencia y Granada durante el siglo XV', Estudios sobre Málaga y el Reino de Granada en el $V$ Centenario de la Conquista, Málaga, 1987, pp. 83-112. 
naves granadinas y conducido a Granada, como represalia por la captura por el capitán de galeras Pere Bernal, posiblemente un valenciano, de una nave granadina que navegaba por Túnez. Pedro el Ceremonioso exigió que se reparase tal agravio, pero Muhammad IV de Granada respondió apresando a los mercaderes valencianos que comerciaban en su reino ${ }^{76}$.

\section{La Baja Andalucía y el área atlántica}

Otra de las zonas hacia la que Valencia orientaba sus intercambios era la Andalucía del Bajo Guadalquivir: Sevilla y los puertos de la fachada atlántica. La trascendencia de la apertura del Estrecho de Gibraltar y el papel de Sevilla en la confluencia de las rutas Mediterráneo-Atlántico son bien conocidos y nos exime hablar de ello ${ }^{77}$. También los contactos con los puertos castellanos quedaron interrumpidos en buena parte de estos años por la guerra de los dos Pedros. A Sevilla hay sólo un asiento en 1351 y un vacío total hasta 1378; en 1381 el número de viajes con productos prohibidos fue de seis, para pasar a 57 en 1392, con una tendencia clara al alza. El regreso a la paz fue un factor decisivo a la hora de potenciar estas relaciones, que la política había vuelto dificiles. Recordemos que en julio de 1325 los jurados de Valencia escribían a los alcaldes de Sevilla ante la amenaza de confiscación de las mercancías de los mercaderes valencianos en la capital hispalense y se quejaban de ello por cuanto habia paz entre Aragón y Castilla, además de estar asegurados en personas y bienes los sevillanos que venían a comerciar a Valencia ${ }^{78}$.

En la costa gaditana eran Algeciras, Cádiz y, sobre todo, Tarifa, los principales destinos de coses vedades. Algeciras fue el más activo en 1351, con 4 salidas de mercaderes valencianos (Llorenç, Ortiz ánchez, Ferrando Maraz y Giner Domenech), que enviaron dobleras y 150 quintales de pez. A Cádiz se llevó en 1357 Ferrando Aragó un arquibanco y una cama, mientras que en 1378 fue Tarifa el principal destino andaluz: siete viajes a cargo de Pedro Coltell, de Tarifa (una cama y un arquibanco); el judío valenciano Salamó Sibili con dos envíos de muebles (una cuna, dos armarios, un arquibanco, una mesita con doblera); Ruiz Martínez, de Cádiz, se llevó un arquibanco; Juan Lorenzo, de Tarifa, varios muebles; Gento, judío tarifeño, una cama con sus pies, y Alfonso Martí, una cama y un arquibanco, es decir un comercio especializado en mobiliario valenciano, destinado al mercado local a a su redistribución por el interior andaluz. Valencia importaba de estos puertos fundamentalmente pescado, fresco o salado, destinado al mercado de la capital, así como granos en periodos de carestía.

76 G. ESCOLANO y J.B. PERALES, Décadas de la historia de la insigne y coronada ciudad y reino de Valencia, Valencia, 1888. III. p. 319.

77 A. SANTAMARIA, “La reconquista de las vías marítimas», La península italiana y el Mediterráneo centro-occidental, pp. 41-129.

78 A.M.V. Manual de Consells, A-1, fol. 236 r. 
Por último, en la vertiente atlántica hay que mencionar dos salidas hacia Lisboa en 1350 (Pere de Tena, mercader de Valencia, con 7 quintales de velas de sebo, y Sancho López con 9 quintales de pez), y otros dos en $1378^{79}$. Son cifras insignificantes comparadas con los 65 viajes de 1392 o los 82 de 1396, pero que reflejan la existencia de unos contactos mercantiles mal conocidos para este periodo. Valencia exportaría las habituales materias primas: pez, velas, manufacturas de madera y productos agrarios, a cambio de pescado portugués.

En 1378 hay un viaje a Galicia a cargo del gallego Gonzalo Delor, que se llevó once puñales. Se importaba pescado y en momentos díficles las autoridades valencianas aseguraban a los percaderes y patrones que desde Galicia trajeran granos y alimentos a Valencia, como se hizo en junio de 1374 con Juan Morino, de Pontevedra ${ }^{80}$.

\section{a) La vía terrestre}

El comercio por tierra sólo aparece parcialmente en nuestras fuentes en 1378, al estar incompleta la documentación. De Aragón se traían a Valencia sobre todo granos, lanas y otras materias primas; y entre los productos vedados sacados de Valencia figuraban puñales, espadas, cobre, hierro a Teruel; puñales a Mosqueruela; hierro a Alcalá de la Selva; 40 espadas guarnecidas que se llevó a la feria de Montalbán Goçalbo Pérez, espadero de Valencia; hierro y cáñamo a Sarrión; hierro y aceite a Mora de Rubielos, en tanto que Albarracín recibió ese año hierro, aceite y acero, 126 espadas y un quintal de arroz.

Los principales destinos, como vemos son Teruel y las comarcas vecinas al reino de Valencia, donde más se dejaba sentir la influencia comercial valenciana, y donde el proceso de humanización de la zona, como lo ha calificado J.A. Sesma, y el despegue de la actividad económica, basado sobre todo en la ganadería lanar y otras materias primas orientadas hacia la exportación, tiene su paralelismo con la consolidación de la actividad mercantil mediterránea, desde Tortosa a Valencia ${ }^{81}$. Los envíos de productos vedados valencianos hacia Zaragoza y otras localidades aragonesas aparecieron en años posteriores, aunque Valencia mantenía viejas relaciones mercantiles con la capital del reino de Aragón, pero sabemos poco de este comercio. De estos años nos ha quedado alguna noticia fragmentaria, como el secuestro en 1345 de bienes de mercaderes valencianos en Zaragoza, lo que hizo que los zaragozanos temieran venir a comerciar a Valencia por temor a represalias y los intercambios se hacían ocultamente en Sagunto y otras villas. Los jurados de Valencia prohibieron que nadie vendiera a gentes de Zaragoza ropas y otras mercancias ocultamente ni las llevara a Sagunto.

79 Diego Pérez, de Lisboa, con un arquibanco de pino; Joan Ramallo, portugués, una hoja de pino, dos vigas y dos cofrecitos.

80 A.M.M. Lletres misives, g3-3, fol. $7 \mathrm{r}-\mathrm{v}$.

81 J.A. SESMA MUÑOZ, "Producción para el mercado, comercio y desarrollo mercantil en espacios interiores (1250-1350): el modelo del sur de Aragón”, Europa en los umbrales de la crisis (12501350). Actas de la XXI Semana de Estudios Medievales. Estella `94, Pamplona, 1995, pp. 205-246. 
Este comercio estaba controlado, por lo general, por mercaderes oriundos de las localidades hacia las que dirigían sus envíos ${ }^{82}$. Otros, como Goçalbo Pérez, espadero de Valencia, eran artesanos que vendían por cuenta propia su producción de armas en el mercado turolense, cuya demanda se centraba en productos alimenticios (arroz, aceite), minerales o metales y armas, cuya excelente calidad les habían proporcionado justa fama en los mercados foráneos.

Castilla fue, sin embargo, el principal receptor de los productos vedados valencianos por vía terrestre, y en 1381, año cercano a la fecha que estudiamos, supuso el $62,2 \%$ de las exportaciones ${ }^{83}$. El escribano no era muy minucioso a la hora de especificar los destinos y bajo el nombre de Castilla se engloba un extenso espacio geográfico que comprendía los distintos territorios de dicha Corona, aunque el grueso de los intercambios se desplegaba en torno a un área que iría desde Alcaraz a Toledo, Huete, Cuenca y Moya, de acuerdo con el siguiente cuadro:

\begin{tabular}{|lll|}
\hline Alcaraz, 1 & Chinchilla, 3 & Requena, 2 \\
Castilla, 36 & Huete, 2 & Toledo, 1 \\
Castillo de Garci Muñoz, 1 & Jumilla, 1 & Uclés, 1 \\
Cuenca, 2 & Moya, 1 & \\
\hline
\end{tabular}

Este comercio corría a cargo de mercaderes valencianos y vecinos de las localidades punto de destino, que al igual que los aragoneses acudían a Valencia a aprovisionarse. Merece destacarse la presencia de judíos castellanos, analizados en otro apartado.

En los productos extraídos merecen destacarse los puñales, con un total de 296 (a Toledo, Huete, Uclés, Requena, Moya, Alcaraz, Jumilla y Castilla), cuchillos (Castilla, Garci Muñoz, Jumilla), aceite (Cuenca, Castilla), hierro, calderas, plomo, hilo de palomar, velas, alquitrán. En algún caso son productos de uso propio, como los que se llevó el honrado Luis Sánchez (2 bacinetes, 5 monturas, 4 sillas viejas, 1 silla de caballo, 5 jacas, una pieza de cotonina, 10 libras de algodón, 2 onzas de hilo de plata, 4 cuchillos y 6 guanteletes).

Era un comercio sujeto a vaivenes políticos y eran frecuentes las represalias comerciales contra mercaderes valencianos o castellanos, como sucedió en 1351 a causa de la licencia de marca concedida por Jaime II a Pere Nadal, de Barcelona, contra súbditos y bienes del rey de Castilla, y que había comenzado a ejercer en Valencia contra castellanos y vasallos de don Juan Manuel, lo que provocó el temor de los ju-

82 Con Teruel negociaron ese año Juan Lopiz, de Teruel; Mossé, judío turolense; Goçalbo Pérez, de Valencia; Martí Navarro; Bertomeu de Canyaveral (4 veces), Guillem Gibert y Ferrando Cebrià, de Valencia. Con Linares de Mora, Ferrando Bonet, de Linares. Con Montalbán, Goçalbo Pérez, espadero de Valencia. A Albarracín fue Juan Soriano (2 veces), Pedro Ortiz,Blasco López, de Albarracín los tres, y Goçalbo Pérez, de Valencia, en dos ocasiones. A Mora de Rubielos, Miguel Cicoler, de Mora. A Sarrión, Benito Sánchez, de esta localidad. Y Rodrigo, de Alcalá de la Selva a esta localidad.

83 R. FERRER NAVARRO, La exportación valenciana, p. 153. 
rados ante posibles represalias contra valencianos en Castilla, con el enorme perjuicio que ello conllevaría para la ciudad, razón por la que pidieron al rey la adopción de medidas correctoras ${ }^{84}$.

Para las autoridades municipales de Valencia la guerra con Castilla fue una contínua fuente de preocupaciones por el riesgo que para la mercadería suponía. De ahí que mantener la paz fuera prioritario para los intereses mercantiles del patriciado urbano. Por eso, cuando a fines de 1374 comenzaron los rumores de que la guerra con Castilla iba a reanudarse, los jurados se mostraron inquietos, y con razón, pues en enero de 1375 llegó la noticia de que una nave castellana cargada de higos había sido apresada y conducida a Mallorca en su ruta a Génova.

Como es natural no faltaron los casos de contrabando, severamente perseguidos por los guardias de los puertos secos con Castilla, y en 1378 el Maestre Racional multó a tres mercaderes por fraudes al fisco y llevarse ocultamente a Castilla coses vedades, recaudando 1.715 sueldos en concepto de multas. Su importancia queda manifiesta si se compara con los 1.131 sueldos, 2 dineros, a los que ascendió el total del impuesto percibido por la saca de productos prohibidos en dicho año.

84 A.R.V. Bailia, 1152 bis, fol. 29 r-v. 